\title{
EVALUATION AND CALIBRATION OF FIXED-WING UAV MOBILE MAPPING SYSTEM EQUIPPED WITH LIDAR AND OPTICAL SENSORS
}

\author{
K. Bakuła ${ }^{1, *}$, W. Ostrowski ${ }^{1}$, M. Pilarska ${ }^{1}$, M. Szender ${ }^{2}$, Z. Kurczyński $^{1}$ \\ ${ }^{1}$ Warsaw University of Technology, Faculty of Geodesy and Cartography, Department of Photogrammetry, Remote Sensing and \\ Spatial Information Systems, Warsaw, Poland - \\ (krzysztof.bakula,wojciech.ostrowski, magdalena.pilarska, zdzislaw.kurczynski)@pw.edu.pl \\ ${ }^{2}$ MSP Marcin Szender, Warsaw, Poland - marcin.szender@uav.com.pl
}

\section{Commission I, WG I/10}

KEY WORDS: UAV, UAS, Multisensor, LiDAR, accuracy, DEM/DTM, photogrammetry

\begin{abstract}
:
In this paper, a mobile mapping system mounted on the UAV is presented and evaluated. The NEO3 UAV platform is an $11 \mathrm{~kg}$ fixed-wing designed by the MSP company. The UAV is equipped with a Riegl miniVUX-1UAV laser scanner, which is integrated with the GNSS/INS system of Applanix APX-15 UAV and two Sony Alfa 6000 cameras collecting images in the following spectrum: visible for the first camera and near-infrared for the second camera. The UAV mobile system presented is dedicated to the acquisition of multisource data for levee monitoring using active and passive remote sensing data. In this paper, the effectiveness of the ultralight laser scanner, which has not been mounted on the fixed-wing platforms so far, was verified in the experiment with respect to data density and accuracy. The example analyses were conducted using ground control points and surfaces measured with a terrestrial laser scanner and visible in point clouds obtained with a dense image matching algorithm. Analyses showed that the achieved accuracy is much related to trajectory accuracy. The final DTM created from the data collected during the float status of the GNSS measurements of the trajectory provided twice less accurate data than during fixed status (vertical error approximately $20 \mathrm{~cm}$ and $10 \mathrm{~cm}$ respectively).
\end{abstract}

\section{INTRODUCTION}

Unmanned Aerial Vehicles (UAVs) are popular in highresolution, periodic measurements. They are mostly used for aerial image acquisition. Over the past years, new trends in the development of UAVs, referring to sensors, involved the application of ultralight laser scanners and integration of various sensors. Only a limited number of ultra-light, UAV-mounted laser scanning systems are described in research papers presenting the scanning systems developed within research projects (Wallace et al., 2012; Droeschel et al., 2013; Kuhnert and Kuhnert, 2013; Tommaselli \& Torres, 2016; Torresan et al., 2018) and turnkey solutions (Glennie et al., 2013; Esposito et al., 2014; Li et al., 2015; Bakuła et al., 2016; 2017; Jozkow et al., 2016; Mittet et al., 2016; Salach et al., 2018). Examples of commercial solutions are presented in Pilarska et al. (2016), but new types of scanning sensors dedicated for UAV platforms appear every year in the market.

UAV systems are usually limited to hovering time when they are mounted on multirotor platforms, which means that the platforms are not able to obtain data for large areas during long flying missions. This is their significant limitation in the comparison to the manned aerial platforms. Such a division in the development of UAV Laser Scanning (ULS) systems was also described in Ostrowski et al. (2017), who introduced two perspectives: the first related to the application of an advanced LiDAR sensor, which collects data using a simulated Beyond Visual Line Of Sight UAV (BVLOS UAV) platform from a high altitude, and the second less expensive UAV laser scanning system, which acquires data from a low-altitude Visual Line Of Sigh. The first group can be more related to fixed-wings solutions and the second with multirotor platforms. This division is also justified by their different application. The data from the first group of platforms can be expected as dense and accurate point clouds and for the second group, the collected data could be an alternative to manned airborne laser scanning.
After the successful creation of LIDAR measurement systems based on UAV platforms, most of them are placed on multirotors, which can be noted in all the papers cited in the first paragraph. The scanning solutions dedicated to unmanned airplanes appear a bit later. The reason for this order is because remote sensing systems for large areas are mostly related to manned photogrammetric systems. In 2017 Phoenix released the TerraHawk VTOL, which is an $18 \mathrm{~kg}$ scanning system with an RGB camera for extended flights up to 3 hours of flight time (www.phoenixlidar.com). In 2018 Delair presented a platform combining LiDAR sensing with an RGB camera to enable highly accurate and high-resolution 3D data collection over large areas. Delair DT26X LiDAR is an $18 \mathrm{~kg}$ fixed-wing UAV with long range flying capabilities - allowing for flight for about 1.5 hours and a communication range of $30 \mathrm{~km}$ (www.delair.aero). It was equipped with miniVUX-1DL by Riegl dedicated for corridor mapping with its field of view of $46^{\circ}$, and the circular scan pattern provides a high point density (www.riegl.com).

Another trend in remote sensing, which was already mentioned, is the platforms' development involving the simultaneous collection of data from different sensors which can provide divergence information about the monitored area and its land cover (Flener et al., 2013; Wallace et al., 2016). Typical integrated data collection can be related to a passive photogrammetric camera and active LiDAR unit.

The final product of the presented system is a high-accurate point cloud with a density of several points per square metre. The point cloud can be used in digital terrain model (DTM) generation. This density is much lower than the typical ULS point cloud from the multirotor platform, however a fixed-wing UAV platform can collect data for much more than dozens of kilometres. Other data processing products are the RGB and 
CIR orthophotos of a Ground Sampling Distance (GSD) of $3 \mathrm{~cm}$. Such a set of multisource data can be used in the multitemporal analysis using the orthophoto analysis and verification of levee damages with the use of vegetation indices (Bakuła et al., 2018).

This article presents a practical example of the multisensorial mobile mapping system mounted on the fixed-wing UAV that offers wide possibilities for less expensive flights that can deliver remote sensing data. It may compete with typical manned aerial data collection considering flight missions over linear objects or small block areas. The article presents the achievable accuracy of the LIDAR system on an unmanned platform moving at high speed with collecting data in long UAV missions.

\section{DATA AND METHODOLOGY OF ANALYSIS}

In this section, the NEO3 platform was presented and the reference data were described. In the last subsection, the evaluation methods used on the collected data were briefly introduced.

\subsection{NEO3 UAV platform}

The fixed-wing NEO3 is equipped with a Riegl miniVUX-1UAV laser scanner, integrated with the GNSS/INS system of Applanix APX-15 UAV, and two Sony Alfa 6000 cameras with a $16 \mathrm{~mm}$ lens. The first camera collects images in the visible spectrum and the second one in the near-infrared. The presented UAV system is dedicated to the acquisition of multi-source data for levee monitoring, using active and passive remote sensing data. The weight of the NEO3 platform, designed by the MSP company, is almost $11 \mathrm{~kg}$. Due to the weight and number of sensors on board, the UAV's start must be performed with the help of a specially designed rail launcher. In Figure 1, the NEO3 platform with sensors' localisation is presented.

a)

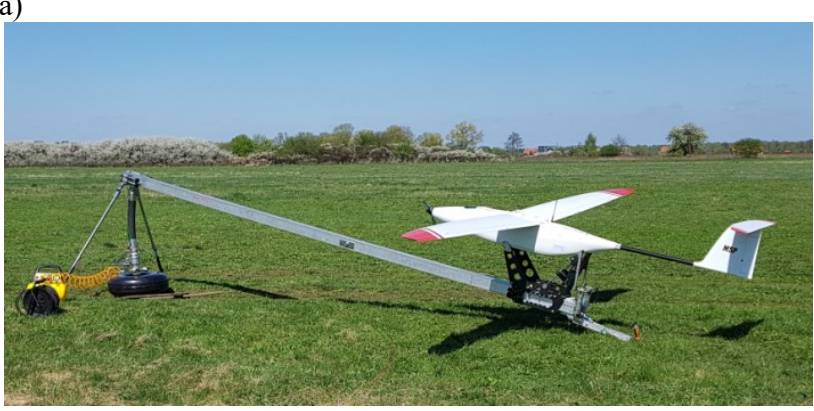

b)

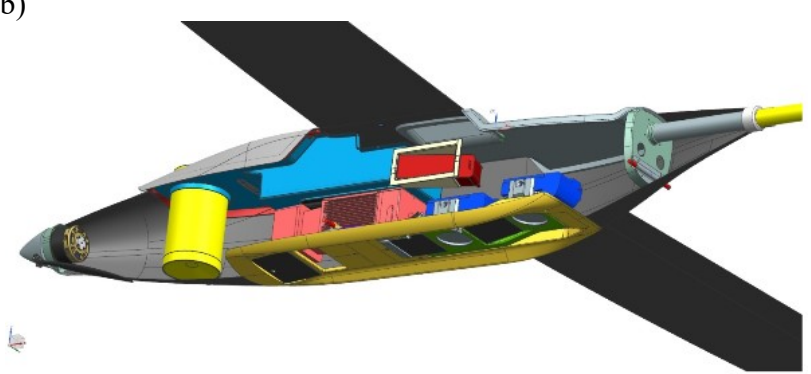

Figure 1. NEO3 on a rail launcher (a) and localisation of the sensors and components in the platform body, in pink (light red) VUX mini-UAV1 scanner in dark blue two Sony Alpha 6000 cameras(b)
During the optimisation tests of NEO3, several volatile sessions were taken from a substitute payload, which imitated the weight of the sensors to find the longest operational time. Test flights were made with three substitute payloads: $13 \mathrm{~kg}, 13.6 \mathrm{~kg}$ and $15.5 \mathrm{~kg}$. The differences in weight were caused by the distinct weight of the batteries. In Table 1, the calculations are provided, such as the predicted flight time and potential length of a single mission (with average speed) for the indicated weight of the platforms' components. After performing the tests, the second variant was selected, because, depending on the conditions, the UAV should provide data from nearly $20 \mathrm{~km}$ of levee in one flight (securing time for a safe return or time for further data collection for the next $20 \mathrm{~km}$ ).

\begin{tabular}{|l|c|c|c|}
\hline $\begin{array}{l}\text { Weights of platform } \\
\text { components [kg] }\end{array}$ & $\begin{array}{c}\text { 1st } \\
\text { variant }\end{array}$ & $\begin{array}{c}\text { 2nd } \\
\text { variant }\end{array}$ & $\begin{array}{c}\text { 3rd } \\
\text { variant }\end{array}$ \\
\hline $\begin{array}{l}\text { body, wings, tail- } \\
\text { plane, parachute }\end{array}$ & 9.016 & 9.016 & 9.016 \\
\hline $\begin{array}{l}\text { batteries: } \\
\text { Tattu 5S 7000mAh } \\
\text { Tattu 5S 10000 mAh } \\
\text { ACi 5s 28000 mAh }\end{array}$ & 1.400 & 2.000 & 3.840 \\
\hline $\begin{array}{l}\text { scanner (Riegl } \\
\text { miniVUX-1 UAV), }\end{array}$ & 1.750 & 1.750 & 1.750 \\
\hline $\begin{array}{l}\text { two cameras (Sony } \\
\text { Alpha 6000) with lens } \\
\text { and cables }\end{array}$ & 0.855 & 0.855 & 0.855 \\
\hline Total weight & 13.021 & 13.621 & 15.461 \\
\hline $\begin{array}{l}\text { Flight time in } \\
\text { temperature of } 10^{\circ} \mathrm{C}\end{array}$ & $25 \mathrm{~min}$ & $35 \mathrm{~min}$ & $100 \mathrm{~min}$ \\
\hline $\begin{array}{l}\text { Potential length of } \\
\text { corridor mapping }\end{array}$ & $28.2 \mathrm{~km}$ & $39.4 \mathrm{~km}$ & $\begin{array}{c}102.6 \\
\mathrm{~km}\end{array}$ \\
\hline
\end{tabular}

Table 1. Calculations of flight possibilities for the NEO3 platform with different weight

\subsection{ULS data used in the experiment}

The UAV data (ULS and UAV images) were obtained on May 14, 2018 over Świniary village near the Vistula River, Mazovia Voivodeship, Poland. The data for the tests and monitoring of $6 \mathrm{~km}$ of levee were collected during the 40minute flight (Fig. 2). This test proved the theoretical calculations of possibility for the flight duration. The overlap between the strips was more than $50 \%$. After the flight over the levees, scanning strips over 22 ha of the above-mentioned village were also carried out. During the tests, 3 strips were oriented perpendicularly to another 3 strips on two heights: 120 and $150 \mathrm{~m}$ were the part of the trajectory, however for the tests only data from a lower height were used.

In Table 2, the statistics for position and orientation corrections are presented. As a next step, the ULS data were oriented in the RiProcess software, developed by the scanner producer. The data were processed using the 13 GCPs, which were also used for RGB image orientation. The signalised control points were manually measured and the total mean value of prior separation was decreased from $0.032 \mathrm{~m}$ to $0.012 \mathrm{~m}$. 
a)

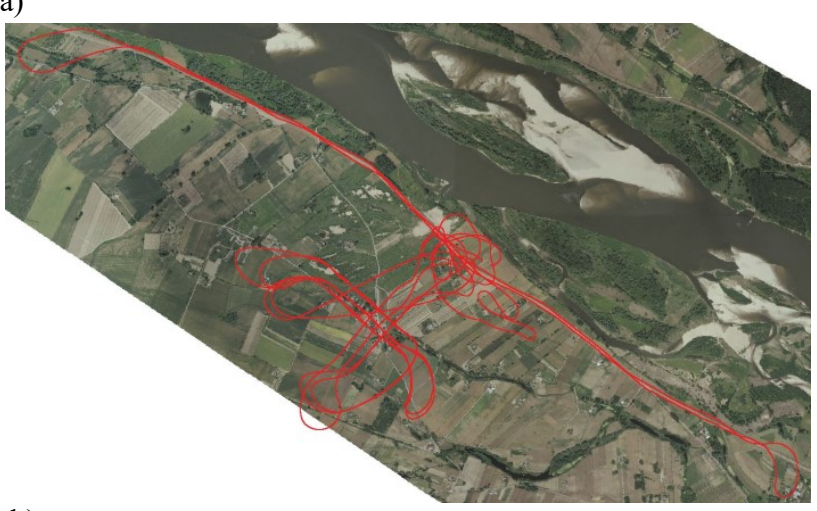

b)

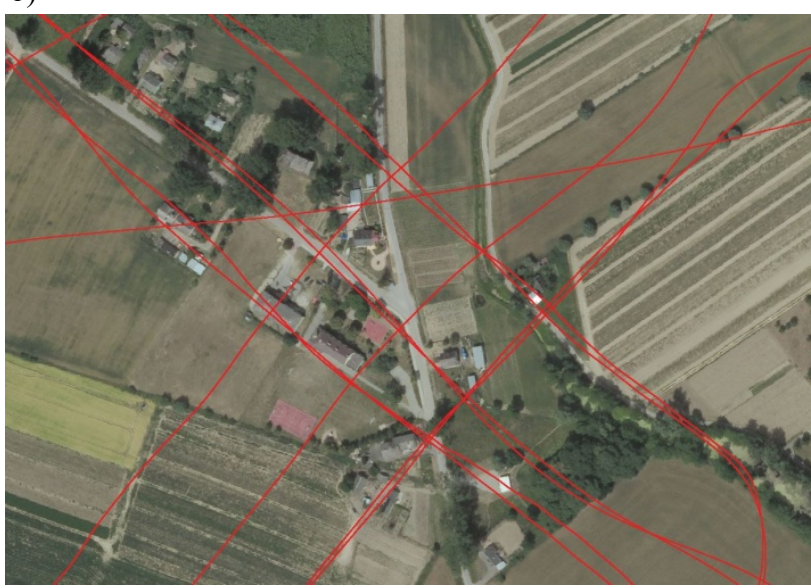

Figure 2. Trajectory of the entire flight over the levees (a) and above Świniary village (b)

\begin{tabular}{|l|l|l|l|}
\hline $\begin{array}{l}\text { Statistics of } \\
\text { Position } \\
\text { Corrections }\end{array}$ & $\begin{array}{l}\text { Absolut } \\
\text { mean [m] }\end{array}$ & RMS [m] & $\begin{array}{l}\text { Maximum } \\
\text { value [m] }\end{array}$ \\
\hline Along-Track & 0.0021 & 0.0029 & -0.0084 \\
\hline Cross-Track & 0.0134 & 0.0208 & 0.0723 \\
\hline Height & 0.1287 & 0.1944 & -0.5416 \\
\hline $\begin{array}{l}\text { Total Positional } \\
\text { Deviation }\end{array}$ & $\mathbf{0 . 1 3 0 4}$ & $\mathbf{0 . 1 9 5 6}$ & $\mathbf{0 . 5 4 3 1}$ \\
\hline $\begin{array}{l}\text { Statistics of } \\
\text { Orientation } \\
\text { Corrections }\end{array}$ & $\begin{array}{l}\text { Absolut } \\
\text { mean [deg] }\end{array}$ & $\begin{array}{l}\text { RMS } \\
{[\mathbf{d e g}]}\end{array}$ & $\begin{array}{l}\text { Maximum } \\
\text { value [deg] }\end{array}$ \\
\hline Roll Angle & 0.10788 & 0.22629 & -1.73622 \\
\hline Pitch Angle & 0.28290 & 0.43346 & -1.28125 \\
\hline Yaw Angle & 0.77430 & 1.31536 & -4.55743 \\
\hline $\begin{array}{l}\text { Total Angular } \\
\text { Deviation }\end{array}$ & $\mathbf{0 . 8 9 8 2 1}$ & $\mathbf{1 . 4 0 3 3 1}$ & $\mathbf{4 . 8 9 0 9 5}$ \\
\hline
\end{tabular}

Table 2. Statistics of position and orientation corrections.

\subsection{Photogrammetric Data}

In the experiment, over 950 images have been collected and they were oriented using 13 signalised control points, which were regularly located over the test area (Fig. 3) and measured with the use of the GNSS RTK technique. They were used as control and check points in the calibration process and the evaluation of the accuracy of the final products. The UAV imagery was processed in the Agisoft PhotoScan 1.2.6 software. From the entire group of surveying points, 6 were used as checkpoints and 7 as control points (GCPs). The Ground Sampling Distance (GSD) of the images was $2.98 \mathrm{~cm}$. In Table 3 , the results of the image orientation are presented. The reprojection error was 1.55 pixel.

\begin{tabular}{|c|c|c|c|c|c|}
\hline $\begin{array}{c}\text { Point } \\
\text { type }\end{array}$ & Point & $\begin{array}{c}\text { Error } \\
{[\mathrm{m}]}\end{array}$ & $\begin{array}{c}\text { X_error } \\
{[\mathrm{m}]}\end{array}$ & $\begin{array}{c}\text { Y_error } \\
{[\mathrm{m}]}\end{array}$ & $\begin{array}{c}\text { Z_error } \\
{[\mathrm{m}]}\end{array}$ \\
\hline control & osn1 & 0.047 & 0.003 & 0.024 & -0.040 \\
\hline control & osn2 & 0.042 & -0.014 & -0.017 & 0.035 \\
\hline control & osn3 & 0.020 & -0.006 & -0.001 & 0.019 \\
\hline control & osn4 & 0.058 & 0.010 & 0.012 & -0.056 \\
\hline control & osn8 & 0.049 & -0.017 & 0.011 & 0.045 \\
\hline control & osn9 & 0.054 & 0.023 & -0.008 & -0.048 \\
\hline control & osn12 & 0.049 & 0.002 & -0.020 & 0.045 \\
\hline check & osn6 & 0.051 & -0.026 & 0.026 & 0.035 \\
\hline check & osn7 & 0.062 & -0.042 & -0.024 & 0.039 \\
\hline check & osn10 & 0.044 & 0.002 & -0.006 & 0.044 \\
\hline check & osn11 & 0.055 & 0.015 & 0.004 & 0.052 \\
\hline check & osn13 & 0.070 & 0.004 & 0.007 & -0.069 \\
\hline check & osn14 & 0.027 & 0.011 & 0.015 & -0.020 \\
\hline total errors & control & $\mathbf{0 . 0 4 7}$ & $\mathbf{c h e c k}$ & $\mathbf{0 . 0 5 3}$ \\
\hline
\end{tabular}

Table 3. List of the checkpoints and control points used for the UAV image orientation

The oriented images were used to generate point clouds using the Dense Image Matching (DIM) algorithm, which could be used to analyse data from the ULS, but also to orthorectify RGB and CIR images and for the further calculation of vegetation indicators using fixed-wings data. The Digital Surface Model (DSM) was also generated from the point cloud, which was useful in the analysis based on surfaces for the ULS data. 


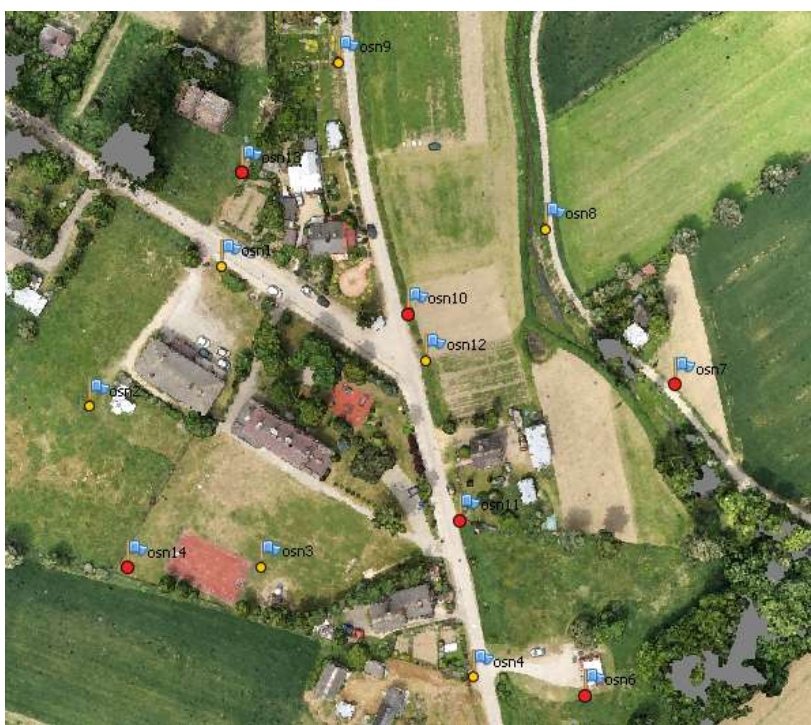

Figure 3. Distribution of the GCPs over the test area (yellow check points, green - control points)

\subsection{Terrestrial Laser Scanning}

For reliable calibration results, terrestrial laser scanning (TLS) point clouds were also used to extract roof planes and the uncovered plane of the road applied in the calibration of the ULS data. Six TLS scans were acquired using the Z+F Imager 5006h laser scanner in super high resolution. The TLS scans were oriented in $\mathrm{Z}+\mathrm{F}$ LaserControl. In order to adjust the scans, signalised points with targets and characteristic points measured in the field were used. The results of the TLS adjustment are contained in Table 4. The perspective view of the oriented TLS point clouds is presented in Figure 4.

\begin{tabular}{|l|c|}
\hline Number of scans & 6 \\
\hline Number of targets & 35 \\
\hline $\begin{array}{l}\text { Relative average deviation (without } \\
\text { absolute orientation) }\end{array}$ & $0.099 \mathrm{~m}$ \\
\hline Average deviation & $0.243 \mathrm{~m}$ \\
\hline Standard deviation & $0.144 \mathrm{~m}$ \\
\hline Maximum deviation & 0.476 \\
\hline
\end{tabular}

Table 4. The results of TLS data orientation.

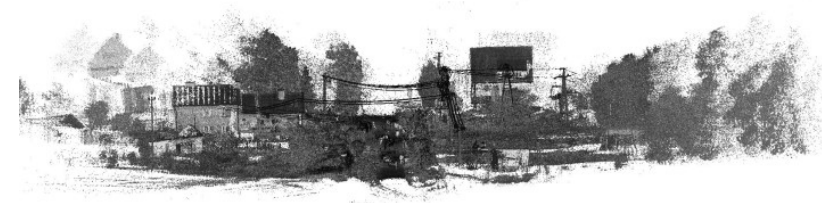

Figure 4. Isometric view of oriented TLS point clouds: view of the intensity of the laser beam

\subsection{Scope of analysis}

In the first part of the analysis, the quality of point clouds collected with ULS and generated from image-based data was examined. The quality of the data was described also by the sigma0 coefficient, which is the standard deviation of the unit weight observation for the moving plane fitting during grid generation from the obtained data. (Pfeifer et al., 2014). The results were compared with the flight parameters to check if the platform speed has no effect on data noise.

The second part of the analysis was based on the DTM created from the aerial data collected with the NEO3 platform equipped with an ultralight scanner and two mirrorless cameras (RGB and CIR). The heights from the generated DTM were compared to the heights from the surveying points measured in a field. In the analysis, the statistic parameters of such a comparison were provided.

The analysis of individual strips on the basis of control points was supplemented by the analysis on the cross-sections of surfaces (roof planes and roads) registered by TLS. Both sources of aerial data were compared by analysing the distance from the ultra-dense TLS point cloud.

The final cloud of points obtained with the ULS did not always meet the quality expectations, therefore we attempted to analyse the received data to identify the reason behind this drop in accuracy. The obtained results were analysed for the dependence on accuracy of the trajectory and the status of the GNSS kinematic measurement of the trajectory. Its parameters were compared with the distances between the individual ULS and DIM data series by analysing the mean distance value and the standard deviation before and after the alignment.

The analyses performed examine the data quality in various approaches based on reference points, point clouds and surfaces in terms of the entire oriented point clouds and division into individual strips with demonstration of the quality of the reference data.

\section{RESULTS}

In this section, the results of all analyses are presented with a short discussion preceding the summary and conclusions.

\subsection{Analysis of the data}

During the processing of LiDAR data following parameters of calibration were determined: lever arms of the scanner, boresight angles. For example the calculated values of leverarms were $1 \mathrm{~cm}$ different than from the direct measurement of the platform and its sketches. Referring to photogrammetric sensors both cameras' offsets and parameters of interior orientation, such as the principal point and distortion parameters, which were also calculated with the self-calibration process were calculated during bundle adjustment.

An analysis of the 3D data collected from the experiment was conducted. In the Table 5, the densities of the point clouds from three sources: ULS (with division for all 6 strips), DIM, and TLS are presented. According to the ULS data, the density of the individual strips varies from 4 to 7 points per square metre, depending on the velocity of the UAV. The platforms' velocity is also included in the table. The mean point density of the ULS strip is 6 points per square metre. The density of the DIM point cloud was approximately 350 points per square metre, while the TLS density is almost 130000 . The sigma 0 parameter provides information about the flatness of the data. According to Table 5, the lowest sigma0 is for DIM data and a bit higher for TLS data, which is the most accurate (and reference) data set in the experiment. For ULS data, the sigma0 value was from 0.03 to $0.04 \mathrm{~m}$, which conveys information about their interior accuracy. 


\begin{tabular}{|c|c|c|c|c|c|c|c|c|}
\hline & \multicolumn{6}{|c|}{ ULS } & \multirow[t]{2}{*}{ DIM } & \multirow[t]{2}{*}{ TLS } \\
\hline & strip 1 & strip 2 & strip 3 & strip 4 & strip 5 & strip 6 & & \\
\hline $\begin{array}{c}\text { density } \\
\text { [points per } \mathrm{m}^{2} \text { ] }\end{array}$ & 7.0 & 4.2 & 6.9 & 5.7 & 3.5 & 6.6 & 356.1 & 128090.2 \\
\hline Average speed & $16 \mathrm{~m} / \mathrm{s}$ & $27 \mathrm{~m} / \mathrm{s}$ & $16 \mathrm{~m} / \mathrm{s}$ & $17 \mathrm{~m} / \mathrm{s}$ & $29 \mathrm{~m} / \mathrm{s}$ & $16 \mathrm{~m} / \mathrm{s}$ & $20 \mathrm{~m} / \mathrm{s}$ & - \\
\hline sigma0 & 0.037 & 0.035 & 0.040 & 0.040 & 0.038 & 0.028 & 0.015 & 0.019 \\
\hline
\end{tabular}

Table 5. Density of obtained ULS, TLS and DIM point clouds

\begin{tabular}{|c|c|c|c|c|c|c|c|}
\hline \multirow{2}{*}{ Statistics } & \multicolumn{9}{|c|}{ ULS } & \multirow{2}{*}{ DIM } \\
\cline { 2 - 8 } & strip 1 & strip 2 & strip 3 & strip 4 & strip 5 & strip 6 & -0.260 \\
\hline min value & -0.346 & -0.256 & -0.153 & -0.508 & -0.262 & -0.153 \\
\hline max value & 0.646 & 0.204 & 0.223 & 0.474 & 0.064 & 0.341 & 0.100 \\
\hline mean value & -0.029 & -0.061 & -0.012 & -0.065 & -0.058 & -0.001 & -0.027 \\
\hline RMS & 0.180 & 0.119 & 0.086 & 0.229 & 0.107 & 0.134 & 0.080 \\
\hline
\end{tabular}

Table 6. Accuracy analysis of the DTM created from different strips of ULS and DIM point cloud based on GNSS surveys.

At this stage of the analysis presented in Table 5, it can be already seen that particular strips of ULS data show roughness of a flat surface of up to $0.04 \mathrm{~m}$. The sigma 0 value at this level, however, is not a grossly bad result for the need to create a DTM of easy terrain. Apart from the accidental errors, such roughness may also be affected by the systematic errors of the sensors, both vertical and horizontal in the case of more difficult terrains.

\subsection{Analysis of DTM for the tested data}

In the second part of the analysis, the accuracy of the DTM generated from individual ULS strips and DIM point clouds was tested. The result presented in Table 6 confirms that based on dozens of control points measured directly in a field, the accuracy of the DTM varied from 0.09 to $0.23 \mathrm{~m}$. The worst results were obtained for strips 1 and 4 . In these strips, the minimum and maximum value of deviations between the DTM height and the direct GNSS measurements in a field was observed. It was a reason of further analysis based on cross sections of the surfaces measured with the TLS.

\subsection{Analysis on surfaces}

After analysing several roof planes and a flat surface of the road, not all analyses were perfect. Figure 5 is an example where the data from the DIM fits perfectly into the TLS data, while sparser ULS point clouds are apparently shifted with approx. 20-30 cm from the reference planes. There are visible fragments of point clouds coming from different strips, which is indicative of a lesser accuracy of the made alignment than it could be noted only in statistics. To quantify this shift in the DTM accuracy context, the spatial distribution of ULS cloud distance differences from much denser TLS data was also performed. The result of this analysis is showed in two histograms in Figure 6.

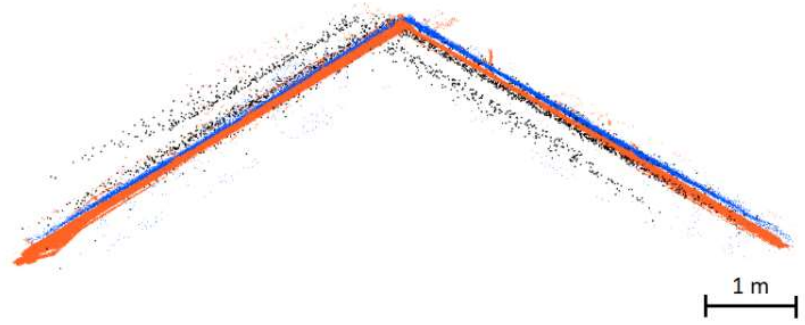

Figure 5. Profile of point clouds for roof planes: ULS (black), DIM (blue) and TLS (orange)

Observing the DIM distances to the TLS, we can see a typical normal distribution indicating an accidental distribution of point clouds and giving the opportunity to assess the accuracy of this data source. The mean distance value $(0.06 \mathrm{~m})$ from the TLS data is similar to the result presented in Table 6 based on $(0.08 \mathrm{~m})$. With respect to the distance histogram for ULS data, a visible overlap of the different accuracy of the different steps can be observed, which also confirms the observation from the previous stage of the analysis. 
Absolute TLS-DIM distance (mean=0.061 m)

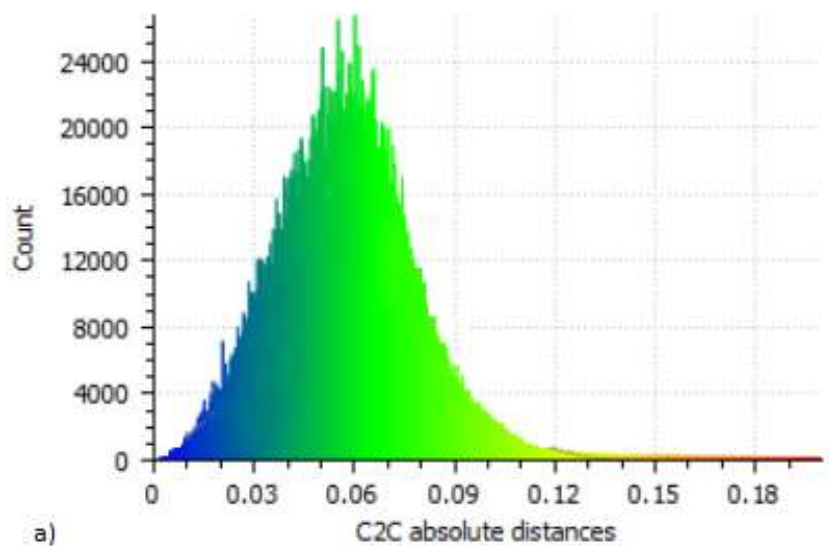

Absolute ULS-TLS distance (mean $=0.078 \mathrm{~m}$ )

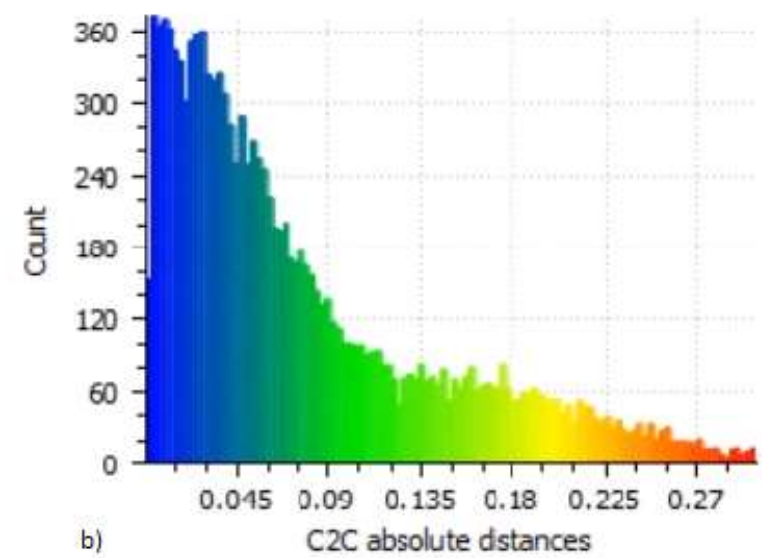

Figure 6. Difference between the DIM (a) and ULS (b) with respect to the TLS point cloud on the flat road surface

\subsection{Relation between trajectory and accuracy of the model}

Seeking the justification of the approximate double decrease in accuracy of the created DTM, which was visible in the analysis based on planes, it was decided to perform an analysis showing the dependence of the trajectory accuracy and its alignment with the final product which was the ULS point cloud and DTM generated from it. In Figure 7, we can see a graphical presentation of the trajectory accuracy of the 6 strips and a comparison of these statistics with the level of GNSS measurement accuracy: RTK fixed solutions, which have the best repeatability (accuracy better than one decimetre) and RTK float solutions, which can be as repeatable as fixed solutions, but can also be in worse accuracy even using surveying points in adjustment. It is shown in Figure 7 that the worst accuracy of the trajectory was for strips 1,2 and 4 . This assumption is confirmed with the indication where the RTK float status was recorded during flight.

In further tests, it was decided to thoroughly analyse the accuracy of the obtained data considering the accuracy of the trajectory, which cannot be done only with control points or randomly located roof planes. In this case, the DIM point cloud which covered the test area more evenly was used because in previous analyses, it was proved that this data source had very high accuracy values tested for control points and there was a lack of visible shifts in the cross section of roof planes. In Table 7 , the trajectory accuracy is presented with the mean value, standard deviation and differences between the DIM and ULS point cloud for individual strips. In this analysis, the surface of the road which was scanned in every strip was considered here to avoid the problem of vegetation filtering. This analysis confirmed that before the adjustment of ULS data, strips which did not meet the fixed status of GNSS measurements in the trajectory definition had a twice higher deviation between the point clouds from both sources. After the alignment, these differences in deviations between individual strips and DIM point clouds are not so visible (despite the mean value for strip 4). a)
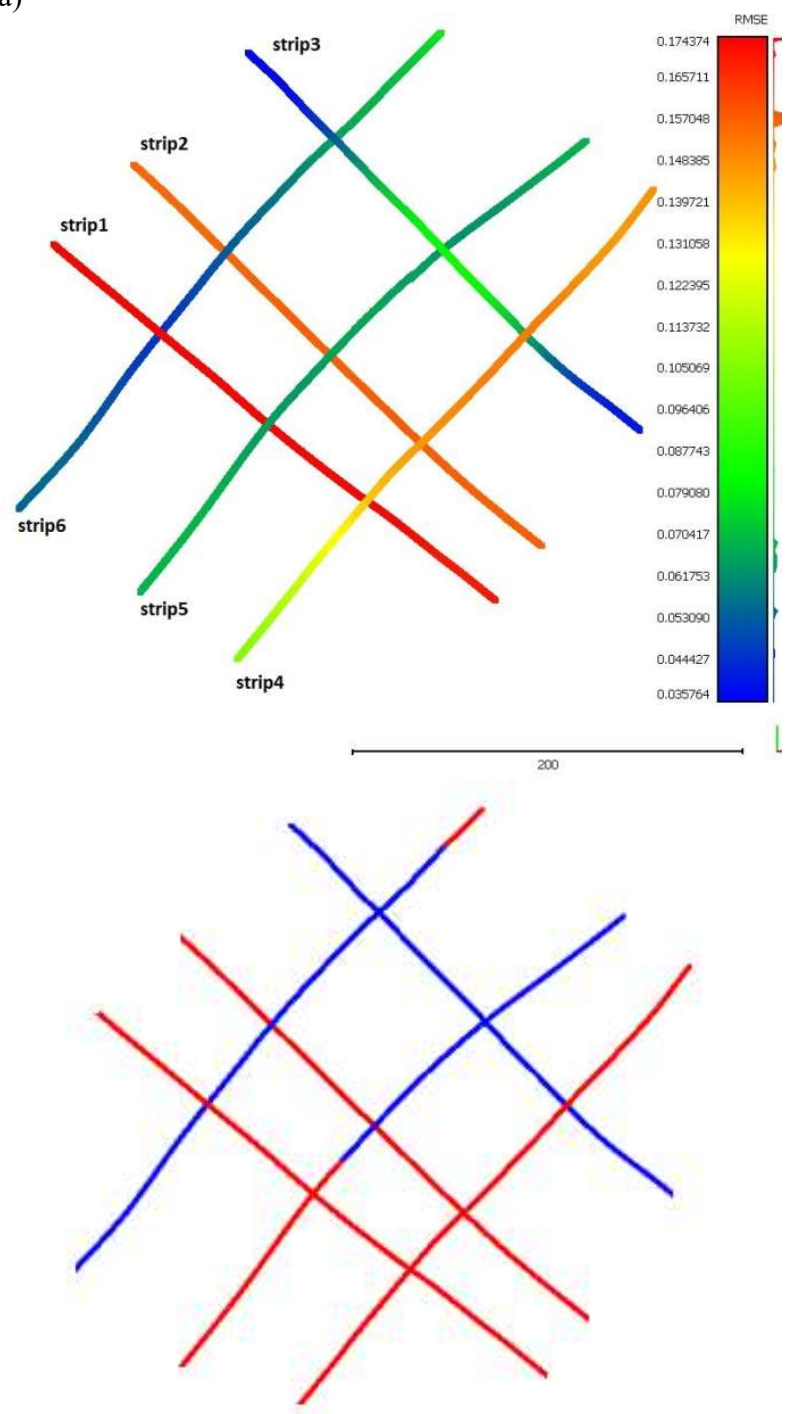

b)

Figure 7. Trajectory accuracy for 6 strips (a) and GNSS solution status (b): blue - RTK fixed, red - RTK float 


\begin{tabular}{|c|c|c|c|c|c|c|}
\hline \multirow{2}{*}{ L.p. } & \multicolumn{2}{|c|}{$\begin{array}{c}\text { Trajectory } \\
\text { accuracy [cm] }\end{array}$} & \multicolumn{3}{|c|}{$\begin{array}{c}\text { Differences between the DIM cloud } \\
\text { and ULS cloud [cm] }\end{array}$} \\
\cline { 4 - 7 } & \multicolumn{2}{|c|}{$\begin{array}{c}\text { before ULS } \\
\text { orientation }\end{array}$} & \multicolumn{2}{|c|}{$\begin{array}{c}\text { after ULS } \\
\text { orientation }\end{array}$} \\
\cline { 2 - 7 } & MEAN & STD & MEAN & STD & MEAN & STD \\
\hline $\begin{array}{c}\text { strip } \\
1\end{array}$ & 17.3 & 0.1 & 36 & 17 & 11 & 9 \\
\hline $\begin{array}{c}\text { strip } \\
2\end{array}$ & 15.7 & 0.1 & 40 & 15 & 13 & 10 \\
\hline $\begin{array}{c}\text { strip } \\
3\end{array}$ & 0.6 & 1.7 & 19 & 15 & 15 & 12 \\
\hline $\begin{array}{c}\text { strip } \\
4\end{array}$ & 14.0 & 1.4 & 32 & 20 & 27 & 18 \\
\hline $\begin{array}{c}\text { strip } \\
5\end{array}$ & 5.8 & 0.1 & 17 & 13 & 14 & 10 \\
\hline $\begin{array}{c}\text { strip } \\
6\end{array}$ & 6.6 & 0.2 & 21 & 14 & 14 & 11 \\
\hline
\end{tabular}

Table 7. Results of trajectory accuracy and differences between photogrammetric and ULS data for individual strips

Figure 8 is the presentation of the results in Table 7 with respect to time. The linear and angular errors of trajectory are presented here with the deviations between the ULS and DIM point cloud. This visualisation highlighted that strips 1,2 and 4 had twice worse results in the tests. The decrease by a few dozens can be caused by many factors related to the accuracy of trajectory, however angular accuracy seems to be crucial here.

\section{SUMMARY AND CONCLUSION}

The article presents a designed platform and its performance in the context of collecting remote sensing data for large areas within an automatic flight mission and the aspect of passive and active sensor calibration providing the opportunity to achieve better results in the future. Such a UAV mobile mapping system can be dedicated to the acquisition of multisource data for using active and passive remote sensing data in a multitemporal analysis using DTM and ortophotos. The contribution of the paper is to introduce the application of a fixed-wing platform equipped with an integrated scanner and camera which has started to be a trend in commercial solutions. Such a highly effective platform may compete with typical manned aerial data collection considering flight missions over linear objects or small block areas.

Examples of the analyses conducted using ground control points and planes measured with TLS and DIM point clouds were included in the practical section of the paper. They indicated that the achieved accuracy of the final DTM created from the data collected during status float with trajectory measurement provided twice less data than during fix status(error approximately $20 \mathrm{~cm}$ and $10 \mathrm{~cm}$ respectively). Changes of the GNSS RTK status and resulted accuracy of trajectory can be caused by short strips and high speed of the fixed-wing platform, problems with initialisation after often returns.

Considering whole analyses, the adjustment of ULS strips did not give all the correct results. The adjustment of the trajectory slightly improved the results for the series which had mostly float status but could worsen the results of the series that had a fix status. The approach of spatial analysis to the distribution of the GNSS status for the platform could improve the achieved accuracy of results when such a problem during data collection appears in the campaign. In that case data with low accuracy can be excluded from the postprocessing or strips with high accuracy can be referenced in alignment.

In the future, further tests of platforms will be conducted and the relation between the trajectory accuracy for the UAS systems and the final result of the DTM will be continued, however, the GNSS solution must be improved to avoid or minimise a problem of float status of the GNSS RTK measurement which definitely influenced the results. The GNSS signal may also be constrained by a number of electronic devices located much closer to each other than in manned aircraft.

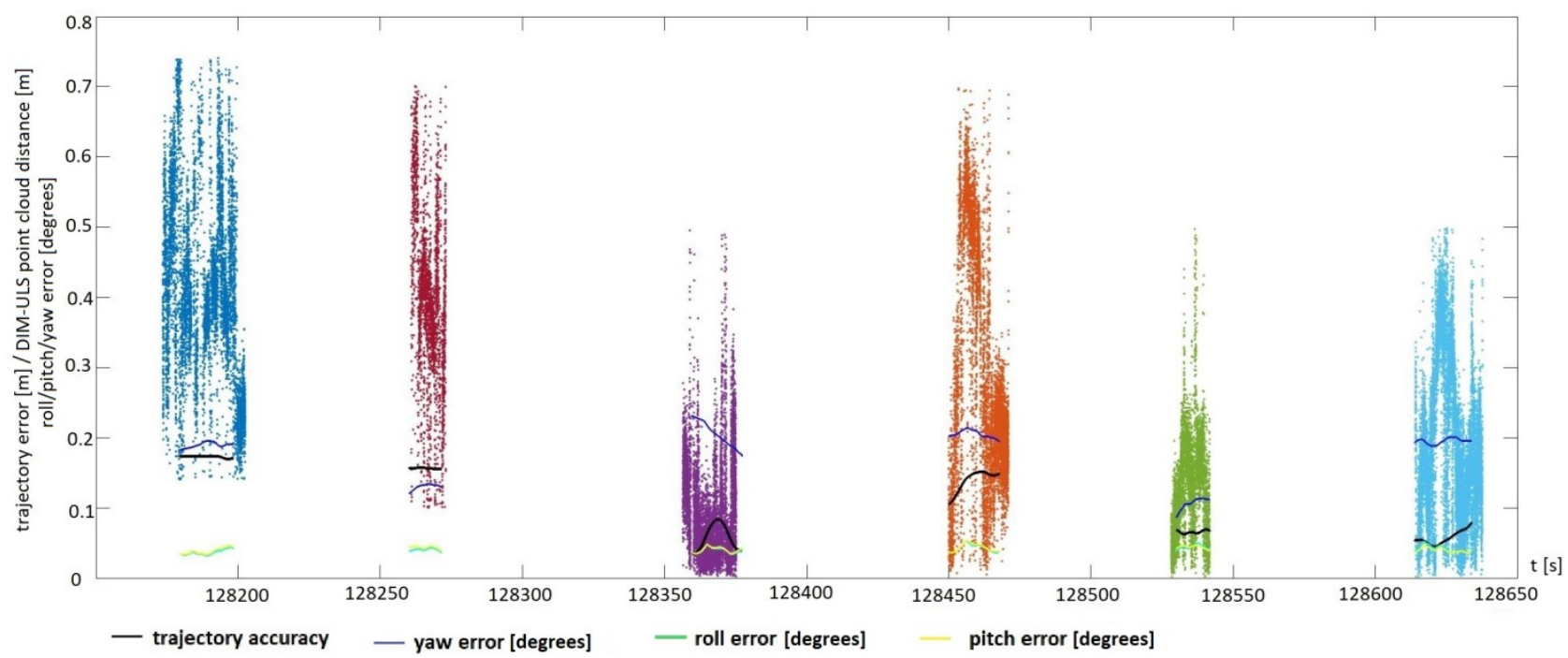

Figure 8 . The relation between trajectory accuracy and the differences between the DIM cloud and ULS cloud presented for individual strips with respect to time. 
The market for laser scanners dedicated to UAV platforms is still quite small. The adaptation of a purchased commercial system with a GNSS and IMU receiver on own platform is not an easy task. The integration with photogrammetric data can help with 3D data evaluation despite photogrammetric images being planned to be used for vegetation indices calculations. The obtained results in the case of the aerial data collected when the trajectory was recorded with the highest accuracy, were satisfied reaching the approximated level of $0.1 \mathrm{~m}$ after digital terrain model generation.

\section{ACKNOWLEDGEMENTS}

This research was financed by the National Centre for Research and Development in Defense, Security Programme within project 'Advanced technologies in the prevention of flood hazard' (SAFEDAM) [grant number DOB-BIO7/06/01/2015].

\section{REFERENCES}

Bakuła, K., Salach, A., Zelaya Wziątek, D., Ostrowski, W., Górski K., Kurczyński Z., 2017. Evaluation of the accuracy of LiDAR data acquired using a UAS for levee monitoring: preliminary results. In: International Journal of Remote Sensing, 38(8-10), pp. 2921-2937,

http://dx.doi.org/10.1080/01431161.2016.1277044

Bakuła, K., Ostrowski, W., Szender, M., Plutecki, W., Salach, A., Górski K., 2016. Possibilities of using LiDAR and photogrammetric data obtained with unmanned aerial system for levees monitoring, In: The International Archives of the Photogrammetry, Remote Sensing and Spatial Information Sciences, XLI-B1, pp. 773-780,

doi:10.5194/isprs-archives-XLI-B1-773-2016

Bakuła, K., Zelaya Wziątek, D., Weintrit, B., Jędryka, M., Pilarska, M., Ryfa, T., and Kurczyński, Z., 2018. Multi-sourced, remote sensing data in levees monitoring: case study of SAFEDAM project. In: The International Archives of the Photogrammetry Remote Sensing and Spatial Information Sciences, XLII-3/W4, pp. 101-108

https://doi.org/10.5194/isprs-archives-XLII-3-W4-101-2018

Droeschel, D., Schreiber, M. and Behnke, S., 2013. Omnidirectional perception for lightweight UAVs using a continuously rotating $3 \mathrm{~d}$ laser scanner. In: International Archives of the Photogrammetry, Remote Sensing and Spatial Information Sciences, XL-1/W2, pp. 107-12.

Esposito, S., Mura, M., Fallavollita, P., Balsi, M., Chirici, G., Oradini, A., and Marchetti, M., 2014. Performance evaluation of lightweight LiDAR for UAV applications. Geoscience and Remote Sensing Symposium (IGARSS), 2014 IEEE International, pp. 792-795.

Flener, C., Vaaja, M., Jaakkola, A., Krooks, A., Kaartinen, H., Kukko, A., Kasvi E., Hyyppä, H., Hyyppä J., and Alho, P. 2013. Seamless mapping of river channels at high resolution using mobile LiDAR and UAV-photography. In: Remote Sensing, 5(12), pp. 6382-6407.

Glennie, C. L., Kusari, A., and Facchin, A., 2016. Calibration and stability analysis of the VLP-16 laser scanner. In: ISPRSInternational Archives of the Photogrammetry, Remote Sensing and Spatial Information Sciences, XL-3/W4: 55-60. doi:10.5194/isprsarchives-XL-3-W4-55-2016.

Jozkow, G., Toth, C., and Grejner-Brzezinska, D., 2016. UAS

Topographic Mapping with Velodyne LiDAR Sensor. In: ISPRS
Annals of the Photogrammetry, Remote Sensing and Spatial Information Sciences, III-1, pp. 201-208, doi:10.5194/isprsannals-III-1-201-2016.

Kuhnert, K.-D., and L. Kuhnert. 2013. Light-weight sensor package for precision $3 \mathrm{~d}$ measurement with micro UAVs eg power-line monitoring. In: ISPRS-International Archives of the Photogrammetry, Remote Sensing and Spatial Information Sciences, XL-1/W2, pp. 235-240.

Li, Z., Yan, Y. Jing, Y., and Zhao, S.G., 2015. The Design and Testing of a LiDAR Platform for a UAV for Heritage Mapping. In: The International Archives of the Photogrammetry, Remote Sensing and Spatial Information Sciences, XL-1/W4, pp. 17-24. doi:10.5194/isprsarchives-XL-1-W4-17-2015.

Mittet, M.-A., Nouira, H., Roynard, X. Goulette, F and Deschaud J.-E.. 2016. Experimental Assessment of the Quanergy M8 LIDAR Sensor. In: ISPRS - International Archives of the Photogrammetry, Remote Sensing and Spatial Information Sciences, XLI-B5, pp. 527-531, doi:10.5194/isprsarchives-XLI-B5-527-2016.

Ostrowski, W., Pilarska M., Górski K., Salach, A., Bakuła, K., 2017. Comparison of the laser scanning solutions for the unmanned aerial vehicles. Archiwum Fotogrametrii, Kartografiii Teledetekcji, vol. 29, pp. 101-129. DOI: 10.14681/afkit.2017.008

Pilarska, M., W. Ostrowski, K. Bakuła, K. Górski, and Z. Kurczyński. 2016. "The potential of light laser scanners developed for unmanned aerial vehicles - the review and accuracy." The International Archives of the Photogrammetry, Remote Sensing and Spatial Information Sciences XLII-2/W2: 87-95. doi:10.5194/isprs-archives-XLII-2-W2-87-2016.

Pfeifer, N.; Mandlburger, G.; Otepka, J.; Karel, W. OPALS-A framework for Airborne Laser Scanning data analysis. Computers, Environment and Urban Systems 2014, 45, 125136.

Salach, A., Bakuła, K., Pilarska, M., Ostrowski, W., Górski, K., and Kurczyński, Z. 2018 .Accuracy assessment of point clouds from LiDAR and dense image matching acquired using the UAV platform for DTM creation In:. ISPRS International Journal of Geo-Information, 8.

Tommaselli, A. M. G., and Torres, F. M., 2016. A light-weight laser scanner for UAV applications. In: International Archives of the Photogrammetry, Remote Sensing \& Spatial Information Sciences, 41.

Torresan, C., Berton, A., Carotenuto, F., Chiavetta, U., Miglietta, F., Zaldei, A., and Gioli, B., 2018. Development and Performance Assessment of a Low-Cost UAV Laser Scanner System (LasUAV). In: Remote Sensing, 10, pp. 1094, doi:10.3390/rs10071094

Wallace, L., A. Lucieer, D. Turner, and C. Watson. 2011. Error assessment and mitigation for hyper-temporal UAV-borne LiDAR surveys of forest inventory. In: Proceedings of 11th International Conference on LiDAR Applications for Assessing Forest Ecosystems SilviLaser 2011. October 16-19, Hobart, Australia 